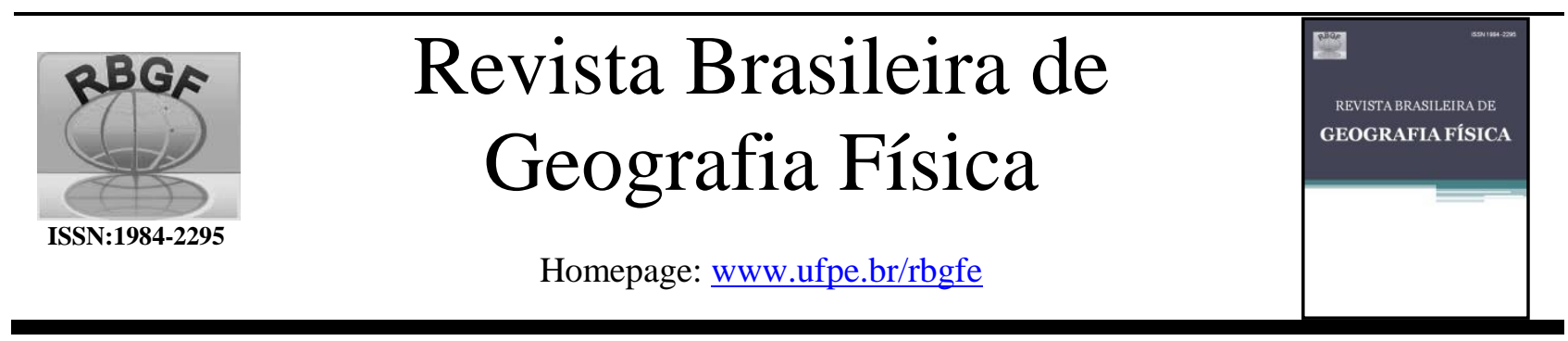

\title{
Análise do Comportamento do Saldo de Radiação Instantâneo em Áreas de Cerrado por Produtos Orbitais
}

\author{
Marcos Esdras Leite ${ }^{1}$, Gabriel Alves Veloso ${ }^{2}$, Manoel Reinaldo Leite ${ }^{3}$, Lucas Augusto Pereira da Silva ${ }^{4}$
}

\begin{abstract}
${ }^{1}$ Professor Doutor do Departamento Geociências/UNIMONTES. Coordenador do Laboratório de Geoprocessamento. Av. Ruy Braga, s/n. Campus Darcy Ribeiro.Vila Mauricéia. Montes Claros/MG. CEP. 39400-000. Marcosleite@ gmail.com. (39) 32298266. ${ }^{2}$ Professor da Faculdade de Geografia da Universidade Federal do Pará - UFPA. Rua Coronel José Porfírio - de 2192/2193 a 3454/3455. Campus Universitário de Altamira, Altamira/PA. CEP. 68372040. gabrielveloso@ gmail.com. (93) 35151079. Professor Mestre do Departamento Geociências/UNIMONTES. Integrante do Laboratório de Geoprocessamento. Av. Ruy Braga, s/n. Campus Darcy Ribeiro.Vila Mauricéia. Montes Claros/MG. CEP. 39400-000. (39) 32298266. Leitemanoel@gamil.com. ${ }^{4}$ Colaborador do laboratório de Geoprocessamento. Graduando em Geografia. Av. Ruy Braga, s/n. Campus Darcy Ribeiro.Vila Mauricéia. Montes Claros/MG. lucaskaio1605@gmail.com. CEP. 39400-000. (39) 32298266. ( autor correspondente).
\end{abstract}

Artigo recebido em 27/06/2018 e aceite em 24/10/2018

\section{R E S U M O}

O objetivo deste trabalho foi analisar por pontos amostrais o saldo de radiação instantâneo em diferentes usos da Terra na Área de Proteção Ambiental (APA) Rio Pandeiros no Norte de Minas Gerais em período seco e chuvoso (08/08/2016 e 27/10/2016). A escolha dessa área de estudo se deu pelo fato de ser uma APA, e, observa-se avanços significativos de ações antrópicas em seu território. Para auxiliar este trabalho, foram utilizadas técnicas de sensoriamento remoto e imagens do Landsat - 8 (OLI/TIRS). O saldo de radiação mostrou ter variação de acordo com cada uso da Terra estabelecido para análise, tendo maiores valores para corpos hídricos e em áreas de vegetação nativa. Destaca-se as áreas de Veredas com os maiores valores, tendo relação com suas características biológicas.

Palavras - Chave: Cerrado, APA Rio Pandeiros, Saldo de radiação e Usos da Terra.

\section{Analyze of Behavior of Net Radiation Instantaneous in the Areas of Cerrado by Orbitals Products}

\begin{abstract}
A B S T R A C T
The objective this work was analyze by sample point the instantaneous net radiation in diferente land uses in the Environment Pretection Area (APA) River Pandeiros in the North Minas Gerais in period dry and rainy (08/08/2016 and 27/10/2016). The choice this study area by the fact of being a APA observe significant advances of anthropic actions in the distribuition territories. For help this work, was basidestechical of remote sensing and images of Landsat -8 (OLI/TIRS). The net radiation showed varied accord in every land use establish for analyze, haved values high for body water and native vegetation. Pointed veredas areas in values high, haved relationship in yours biologicals characteristic. Keywords: Cerrado, APA River Pandeiros, Net radiationand Land uses.
\end{abstract}

\section{Introdução}

O Cerrado Brasileiro ocupa área aproximada de $2.000 .000 \mathrm{~km}^{2}$, localizado dentro do polígono formado pelas coordenadas de $2^{\circ} 34^{\prime} \mathrm{e}$ $24^{\circ} 68^{\prime}$ de latitude Sul e $41^{\circ} 52^{\prime}$ e $60^{\circ} 10^{\prime}$ de longitude Oeste, faz fronteira com os biomas Amazônico, Caatinga, Mata Atlântica e Pantanal. Outrora, a formação natural abrangia áreas de doze Estados e o Distrito Federal do Brasil.

Sabe-se que este Bioma apresenta fauna e flora diversificada, estando associado as suas peculiaridades espaciais, que propiciam ampla variação de espécies. Estas nuances espaciais diversificadas estão relacionadas ao contexto geofísico, sobretudo considerando as morfoestruturas, morfoesculturas, diversificada pedologia, além da climatologia que atua de maneira efetiva na modelagem da epiderme da Terra. Assim, pode-se afirmar que há grande variabilidade florística em suas formações vegetacionais, e podem ser classificadas em: mata ciliar, mata de galeria, mata seca (decídua, semidecídua e sempre-verde), cerradão, Parque de Cerrado (estando interligado a características geomorfológicas) campo limpo, campo sujo, campo rupestre, cerrado rupestre, sentido restrito, subsistemas de veredas, Palmeirais e ademais. 
Este bioma pode se enquadrar entre os hotspots da biodiversidade, tanto por seus elementos naturais, quanto pela intensa ocupação antropogênica, sendo que de acordo com MMA (s/d) o conceito de hotspots é para áreas com grande riqueza biológica que vem sofrendo ameaças.

Os avanços nas áreas do Cerrado se dão pela lógica de desenvolvimento das civilizações, e isso impõe que as mesmas adotem modelos econômicos para suprir suas necessidades, desde os avanços agrícolas em busca de alimentos, até a concentração e crescimento industrial (Silva et al., 2017).

Dessa forma, ao observar as áreas de Cerrado demonstrando as diferentes nuances tanto em aspectos naturais, quanto em antropogênicos, pode-se imaginar o arcabouço científico que o mesmo representa, principalmente ao direcionar as atenções para as questões climáticas que vêm ganhando enfoque nas discussões científicas pelo mundo.

Essa grande variação florestal e de ocupação no Cerrado, pode ser condicionante em fenômenos à superfície, já que as mudanças no uso e ocupação da terra em unidades de bacias hidrográficas podem provocar significativas alterações no balanço de energia (BE) e, por conseguinte, afetar a evapotranspiração, e antecedendo isso o Saldo de Radiação (Rn), que de acordo com Santos et al., (2014)resulta no balanço entre os fluxos radiativos descendentes (BOC) e ascendentes (BOL) que atuam na superfície; é responsável pelo controle da fotossíntese, evaporação, aquecimento do ar e do solo. Este balanço depende principalmente das condições atmosféricas, da radiação solar global, do albedo (poder de reflexão da superfície), temperatura e emissividade da superfície (Oliveira et al., 2015), apresentando variação temporal e espacial que impactam fortemente as trocas de calor e massa entre superfície e atmosfera.

Conforme Matos et al., (2016), a quantificação do saldo de radiação é de grande relevância para a estimativa da evapotranspiração e consequente avaliação de déficits hídricos, sendo este, um grave problema às atividades agropecuárias em regiões semiáridas. E também nas trocas de energia e massa (Silva et al., 2016).

A sua determinação e mensuração direta pode ser feita com aparelhos específicos, como o saldo radiômetro; já que a medida deste elemento não é rotineira em estações meteorológicas (Lopes et al., 2013); no entanto, essas medições são para representação de áreas de pequena dimensão e boa homogeneidade, com custos de aquisição e manutenção elevados, o que restringe sua ampla utilização.

Dessa maneira, o meio técnico vem buscando novas formas para sanar as necessidades de compreensão dessas variáveis. E os estudiosos em ciências vem adotando de técnicas de Sensoriamento Remoto, e, nos últimos anos o SR) tem assumido grande importância no monitoramento de diversos fenômenos meteorológicos e ambientais oferecendo suporte nas previsões de tempo e melhor entendimento das mudanças climáticas (Bezerra et al., 2014), além de auxiliar no planejamento agroecológico. podendo tracejar analiticamente cenários e formas de subsidiar a tomada de decisão de gestores, inferindo assim auxilio às políticas públicas.

As principais vantagens de dispor desta ciência como suporte técnico nas análises, é o fato da mesma obter informações da superfície da Terra sem que haja contato com a mesma, isso através da interação da radiação eletromagnética entre os corpos na superfície e os sensores abordo, por meio de intervalos de faixas espectrais, variando do vermelho visível, infravermelho próximo, médio e o termal. Conforme Silva et al., (2015) dentre as técnicas de SR existentes para a determinação do saldo de radiação e da evapotranspiração, o algoritmo Surface Energy Balance Algorithm for Land (SEBAL) é recorrentemente utilizado em diversas partes do globo.

Esse algoritmo vem sendo testado em diversos grupos da comunidade científica, visando as análises das dinâmicas exercidas pelas ações antrópicas, bem como: nos sistemas termodinâmicos, as variações de cobertura vegetal pelos índices de vegetação, o uso do albedo de superfície para compreender a dinâmica ambiental, as trocas e variações energéticas entre o sistema Terra-Atmosfera, além da compreensão da perda de água da superfície, sendo esta última uma forma substancial para a gestão dos recursos hídricos, e consequentemente na organização das sociedades, pois como visto em Viero et al., (2014) o homem desde os primórdios das colonizações possuía a água como principal fonte de sobrevivência, tanto para sua dessedentação quanto no uso dos sistemas irrigados, tornando a água uma fonte de energia (conversão em alimentos).

O SEBAL foi validadoem diversas regiões do planeta, e suas constantes matemáticas foram impostas a várias condições geofísicas, desde desertos a florestas úmidas como a Amazônia. 
Conforme Lopes et al., (2014), para o SEBAL tem-se a necessidade dedados de imagens digitais, que registram a radiação térmica infravermelha, além da radiação do visível e do infravermelho próximo, determinando o balanço energético da superfície pixel a pixel.

Destarte, este trabalho tem por objetivo de pesquisa, analisar por meio de pontos amostrais o saldo de radiação instantâneo em diferentes usos da Terra na Área de Proteção Ambiental (APA) Rio Pandeiros no Norte de Minas Gerais em período seco e chuvoso (08/08/2016 e 27/10/2016, respectivamente).

A escolha dessa área de estudo se deu pelo fato de ser uma Área de Proteção Ambiental, e, mesmo assim observa-se avanços significativos de áreas antropogênicas em sua distribuição territorial, tendo em vista que isso pode acarretar em distorções no balanço de radiação, sendo que no entender de Silva et al., (2017) as alterações nos revestimentos naturais da superfície tendem a levar a alterações no balanço de radiação tanto na superfície quanto na atmosfera.

\section{Material e métodos}

Caracterização da área de estudo

Do ponto de vista ambiental, a APA Rio Pandeiros é considerada maior área de preservação ambiental do estado de Minas Gerais, estando localizada no Norte de Minas Gerais, entre as coordenadas $15^{\circ} 02^{\prime} 50^{\prime \prime}$ e $15^{\circ} 43^{\prime} 38^{\prime \prime}$ de latitude $\mathrm{S}$ e $45^{\circ} 17^{\prime} 26^{\prime \prime}$ e $44^{\circ} 37^{\prime} 29^{\prime \prime}$ de longitude W. Esta área de preservação ambiental foi criada pela Lei 11.901, de 01/09/1995, abrangendo os municípios de Januária, Bonito de Minas e Cônego Marinho.

No diz respeito ao quadro topográfico, a APA do Rio Pandeiros detém em seu território altitudes de 449 e 846 metros, conforme a figura 1:

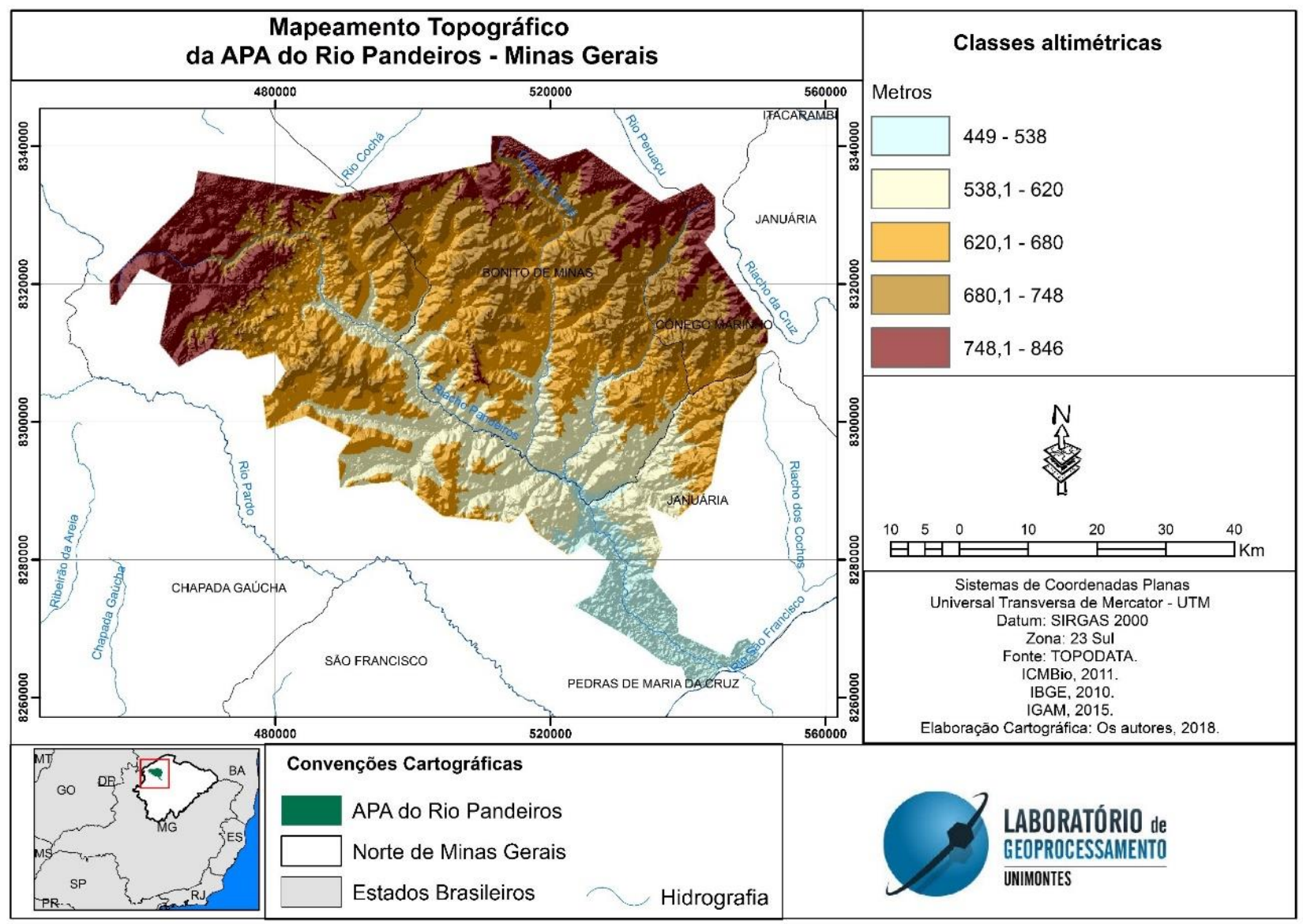

Figura 1. Mapa topográfico da APA Rio Pandeiros.

Segundo Almeida (2016) citado por Leite et al., (2018) a área comporta toda a bacia hidrográfica do Rio Pandeiros, afluente à margem esquerda da macrobacia do Rio São Francisco. 
Em relação ao contexto climático, se destaca o clima Tropical Subúmido-Úmido, com proximidade ao limite do Subúmido-Seco, com períodos de chuvas concentradas entre os meses de outubro a março. A Geologia da APA, de acordo com CODEMIG (2014) se subdivide pelo grupo areado, Complexo Januária, Grupo Urucúia, cobertura superficial indiferenciada, Formação Serra de Santa Helena, Formação Sete Lagoas e depósito aluvial, conforme a figura 2 e tabela 1:

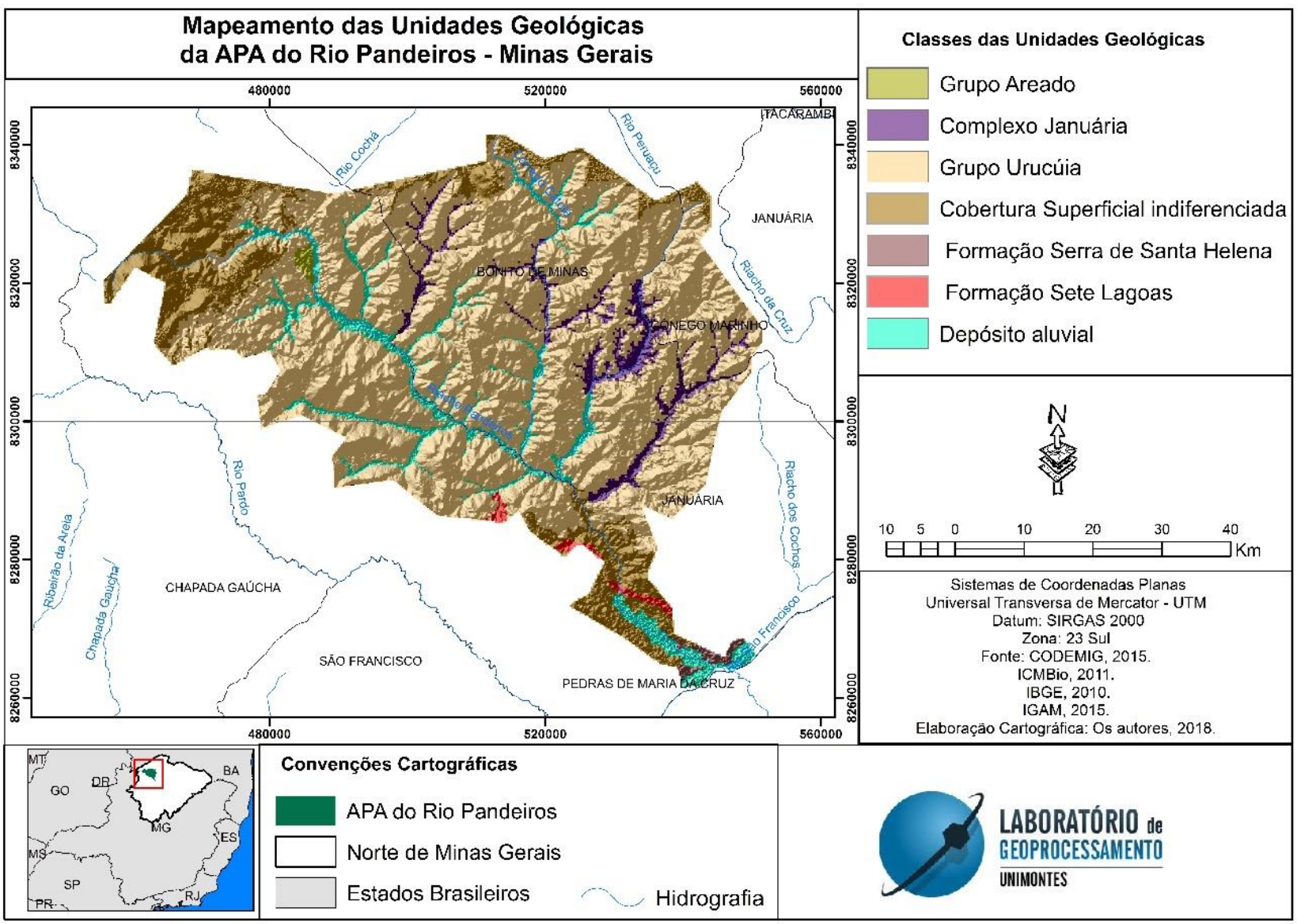

Figura 2. Geologia da APA do Rio Pandeiros

Tabela 1 - Percentual da Geologia da APA do Rio Pandeiros.

\begin{tabular}{l||l}
\hline Unidade Geológica & $\%\left(\mathrm{Km}^{2}\right)$ \\
\hline Grupo areado & 0,29 \\
\hline Complexo Januária & 4,25 \\
\hline Grupo Urucúia & 72,84 \\
\hline Cobertura superficial indiferenciada & 15,16 \\
\hline Formação Serra de Santa Helena & 0,47 \\
\hline Formação Sete Lagoas & 0,62 \\
\hline Depósito aluvial & 6,37 \\
\hline
\end{tabular}

Fonte: CODEMIG, 2014. Org. LAPS,2017. 
A área de estudo possui um vasto panorama florístico, tendo em sua extensão áreas predominantemente do Bioma Cerrado, com variações de campos cerrado, matas secas, e subsistema florestal de Veredas.

\section{Procedimentos Técnicos Operacionais}

Para executar essa pesquisa, utilizou-se produtos cartográficos dos sensores OLI e TIRS do satélite Landsat -8 , referentes às órbitas/ponto 219/71.

A escolha destes produtos mantém relação com o objetivo de estudo proposto, uma vez que, para esta análise foram selecionados produtos em período chuvoso e seco de acordo com a sazonalidade da localidade.
Os dados satelitários foram obtidos no site do Instituto Nacional de Pesquisas Espaciais (INPE), sendo estes disponibilizados gratuitamente.

Foram utilizadas imagens para o ano de 2016 nos períodos seco e chuvoso, sendo 08/08/2016 e 27/10/2016. A escolha destes períodos foi para compreender a variação do saldo de radiação em relação à sazonalidade climática da área de estudo.

$\mathrm{Da}$ posse das imagens, realizou-se $\mathrm{o}$ processamento digital, iniciado a partir da composição das imagens, utilizando os seguintes canais: 2,3,4,5,6,7 e 10. Esta composição foi realizada no Erdas IMAGINE 2014, através da ferramenta Layer Stack. Na tabela 1 estão as características das bandas:

Tabela 2 - Características dos canais.

\begin{tabular}{r||l||l||l}
\hline Bandas & $\begin{array}{l}\text { Comprimento de onda } \\
\text { (micrometros })\end{array}$ & $\begin{array}{l}\text { Resolução Espacial } \\
\text { (metros })\end{array}$ \\
\hline 2 & Azul & $0.450-0.51$ & 30 \\
4 & Visível Verde & $0.53-0.59$ & 30 \\
5 & Visível Vermelho & $0.64-0.67$ & 30 \\
6 & Infravermelho Próximo & $0.85-0.88$ & 30 \\
7 & Infravermelho Médio/SWIR & $1.57-1.65$ & 30 \\
10 & Infravermelho Médio/SWIR & $2.11-2.19$ & 30 \\
& (TIRS) 1 & $10.60-11.19$ & 100 \\
\hline
\end{tabular}

Fonte: Serviço Geológico dos E.U.A Org. Os Autores.

Em segundo momento foi realizada a fotoleitura das imagens para a identificação e discriminação dos usos da Terra, após isso, realizou-se o mapeamento do uso da Terra.

Para a realização deste procedimento, foi feita a classificação supervisionada, permite que o analista esteja constantemente em interação com o sistema de análise digital, dispondo de informações sobre a área de estudo, que neste caso foi a APA do Rio Pandeiros.

Esta classificação foi através do classificador MaxVer, ou seja, a classificação por máxima verossimilhança (MaxVer), que considera que em cada classe de análise existe uma distribuição normal (Sothe et al.,2017). Na concepção de Lu et al., (2014) o Maxver se norteiam probabilidade de um pixel pertencer a determinada classe e leva em consideração variabilidade das classes usando a matriz de covariância.

Estabeleceu-se os seguintes usos da Terra para análise: Agricultura, Cerrado, Vereda, Afloramento Rochoso Mata Seca, Pastagem, Solo Exposto, campo cerrado e Água. 
Em terceiro momento, foi mapeado o saldo de radiação instantâneo e, este mapeamento foi executado no software ERDAS 2014, destacando a ferramenta Model Maker que é um modelador matemático que permite a entrada em blocos das imagens de satélite no algoritmo SEBAL e a operação dos cálculos propostos no algoritmo, além de variáveis condicionais.

Os parâmetros das imagens disponibilizadas nos cabeçalhos das mesmas, como tempo central (GMT), orientação da imagem, azimute do Sol e ângulo de elevação do Sol, e dados de calibração fornecidos pelo serviço geológico dos E.U.A, são utilizados como dados de calibração do algoritmo SEBAL.

A seguir será explicitado por meio de expressões matemáticas o processo de obtenção do saldo de radiação no modelo SEBAL:

\section{Etapa 1: Radiância}

Esta etapa consiste na conversão dos números digitais (ND) em radiância espectral monocromática que representa a radiação solar refletida e a radiação emitida pela Terra, para as bandas 2,3,4,5,6,7 e 10. Utilizou a equação 01(USGS, 2016).

$$
L_{\lambda}=M_{L} Q_{c a l}+A_{L(01)}
$$

Sendo: atmosfera.

$\mathrm{L} \lambda=$ radiância espectral no topo da

$\mathrm{ML}=$ fator multiplicativo de

reescalonamento para cada banda (disponibilizado no metadados da imagem).

Qcal = número digital para cada pixel.

$\mathrm{AL}=$ fator aditivo de reescalonamento

para cada banda (disponibilizado no metadados da imagem).

\section{Etapa 2: Reflectância}

A reflectância é a razão entre o fluxo de radiação solar refletido pela superfície e o fluxo de radiação global incidente, para tal, utilizou-se a equação 02:

$$
\begin{aligned}
& \rho_{\lambda}^{\prime}=M_{\rho} Q_{c a l}+A_{\rho(02)} \\
& \text { Sendo: } \\
& \rho \lambda^{\prime}=\text { não apresenta correção para o ângulo }
\end{aligned}
$$$$
\text { solar }
$$

$\mathrm{M} \rho=$ fator multiplicativo de reescalonamento para cada banda (disponível nos metadados da imagem)

$\mathrm{A} \rho=$ fator aditivo de reescalonamento para cada banda (disponível nos metadados da imagem).

\section{Etapa 3: Albedo}

O albedo de superfície pode ser entendido como o coeficiente de reflexão da superfície para a radiação de onda curta, corrigidos os efeitos atmosféricos. O albedo de superfície sofre influência de variáveis, desde as características da superfície até a ocorrência de ventos fortes que alteram a direção angular do dossel vegetativo e até pela presença de irrigação em determinada área. Por isso mesmo, trata-se de um importante indicador qualitativo das atividades antrópicas. A obtenção do albedo de superfície se deu por meio da equação 03:

$$
\alpha=\frac{\alpha_{\text {toa }}-\alpha_{p}}{\tau_{s w}{ }^{2}}
$$

Em que: $\alpha$ toa $=$ albedo planetário; $\alpha p=$ radiação solar refletida pela atmosfera variando de 0,025 a 0,04 . No caso específico deste trabalho, utilizou-se $\mathrm{o}$ valor de 0,$025 ; \quad \tau \mathrm{sw}=$ transmissividade da atmosfera que nas condições de transparência calcula-se utilizando a equação 04 de acordo com Alves et al (2017).

$$
\tau_{s w}=0,75+2 \times 10^{-5} z
$$

Em que: $\mathrm{z}=$ altitude em metros de cada pixel da imagem.

\section{Etapa 4: Saldo de radiação}

O Saldo ou Balanço de Radiação indica a radiaçãodisponível em superfície, em que devem serconsideradas tanto a radiação de onda longa quantoa radiação de onda curta. Neste trabalho adotou-se aseguinte equação para o cálculo (equação 05) do saldo de radiação(Rn):

$$
\begin{aligned}
R n= & (1-\alpha \sup ) R c \downarrow+R L \downarrow-R L \uparrow \\
& -(1-\varepsilon s) R L \downarrow, \quad(05)
\end{aligned}
$$

Em que: asup é o albedo da superfície (adimensional), Rc $\downarrow$ representa a radiação de onda curta incidente(W m-2), RL $\downarrow$ é a radiação de onda 
longa incidente(W m-2), $\mathrm{RL} \uparrow$ é a radiação de onda longa emitida pelasuperfície (W $\mathrm{m}-2)$ e $\varepsilon s$ é a emissividade da superfície(adimensional).

Da posse dos dados sobre saldo de radiação, foi realizada a coleta de pontos amostrais nas cartas de saldo de radiação, considerando os diferentes usos da terra para mensurar $\mathrm{o}$ comportamento do Rnpontualmente, feito isso em ambiente computacional, realizou-se a análise estatística e gerou-se gráfico temático para compreender a variação do $\mathrm{Rn}$.

\section{Resultados e discussão}

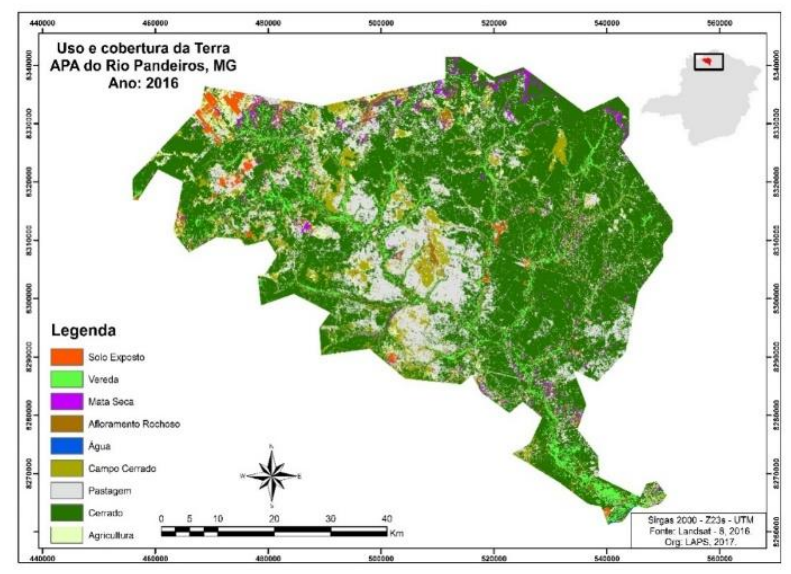

Figura 3. Mapa de uso da Terra da APA em 2016.

Tabela 3 - Percentual de uso da Terra na APA do Rio Pandeiros.

\begin{tabular}{l||r}
\hline Usos da Terra & $\mathrm{Km}^{2}$ em percentual \\
\hline Solo Exposto & 1,46 \\
Vereda & 4,82 \\
Mata Seca & 2,04 \\
Afloramento Rochoso & 1,66 \\
Água & 0,03 \\
Campo Cerrado & 6,4 \\
Pastagem & 19,54 \\
Cerrado & 59,85 \\
Agricultura & 4,2 \\
\hline
\end{tabular}

Leite, M. E., Veloso, G. A., Leite, M. R., Silva, L. A. P. 
Tabela 4 - Características dos usos da Terra.

\begin{tabular}{|c|c|}
\hline SUT & Características \\
\hline Agricultura & Áreas irrigadas e não irrigadas, e cultivos permanentes. \\
\hline Água & Corpos hídricos ao longo do território da bacia. \\
\hline Cerrado & $\begin{array}{l}\text { Vegetação com grandes extensões e representada por cerradão e Cerrado } \\
\text { típico. }\end{array}$ \\
\hline Campo Cerrado & Composto por vegetação rasteira, gramíneas e arbustos em extensões da bacia. \\
\hline Vereda & Toda vegetação que margeia os corpos hídricos da APA Rio Pandeiros. \\
\hline Mata Seca & $\begin{array}{l}\text { Áreas com vegetação em encostas de serras, com características de vegetação } \\
\text { espaçada e médio porte. }\end{array}$ \\
\hline Afloramento Rochoso & Áreas com rochas expostas sem cobertura vegetal. \\
\hline Pastagem & $\begin{array}{l}\text { Áreas divididas em pastagem melhorada e degradada, com fenologia de baixo } \\
\text { porte e rasteira. }\end{array}$ \\
\hline Solo Exposto & $\begin{array}{l}\text { São áreas onde é escassa a vegetação, deixando o solo em total descobrimento. } \\
\text { Além de áreas destinadas ao preparo de cultivos. }\end{array}$ \\
\hline
\end{tabular}

Após o mapeamento, realizou-se as abordagens técnicas e teóricas acerca do saldo de radiação em diferentes sistemas de usos da Terra. O saldo de radiação é influenciado além do tipo de uso da Terra, por variações meteorológicas locais, a exemplo os índices pluviométricos, e, nesta pesquisa fez-se necessário analisar os índices pluviométricos para o ano de 2016 e argumentar acerca das variações do saldo de radiação.
No gráfico 1 estão os índices pluviométricos para a área de estudo de acordo com a estação meteorológica do Instituto Nacional de Meteorologia (INMET) situada no município de Januária inserido da extensão da APA Rio Pandeiros. 


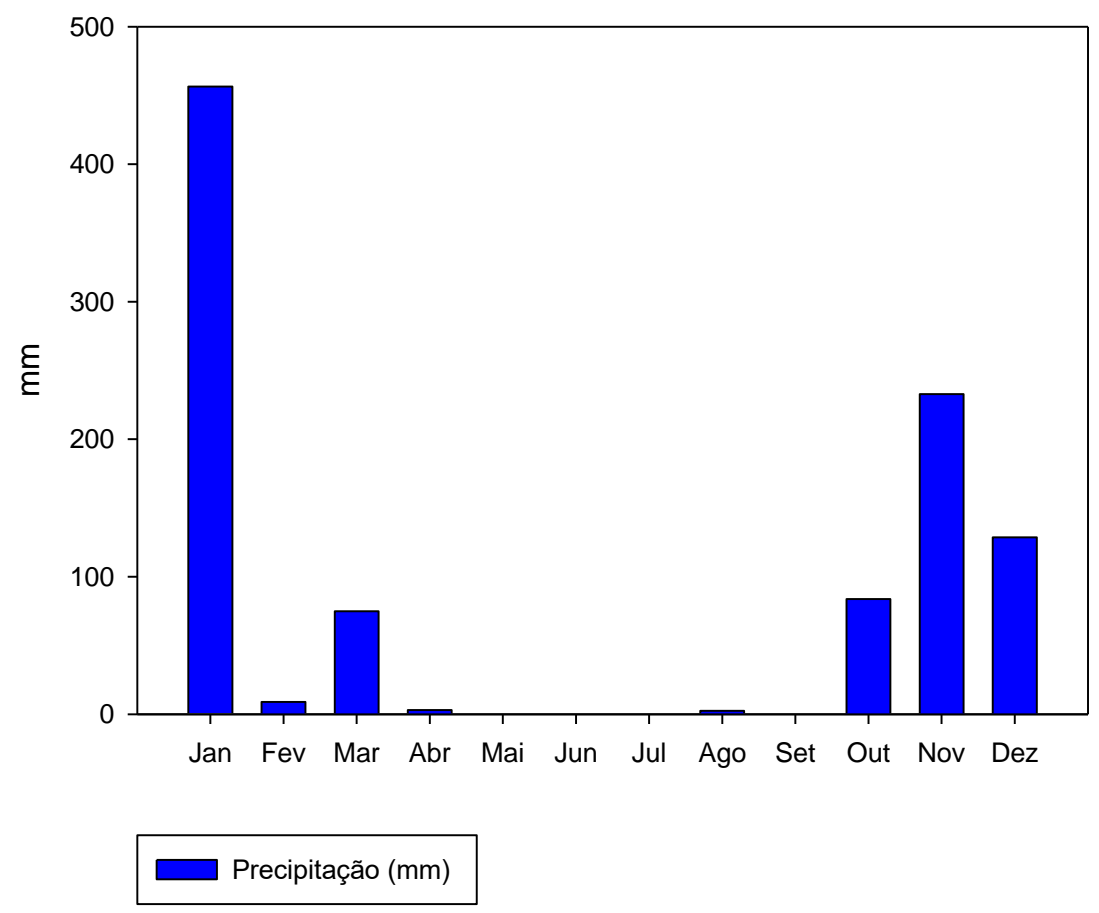

Gráfico 1. Índices Pluviométricos para área de estudo. Fonte. INMET, 2016. Org. LAPS,2017.

Analisando o gráfico acima, percebe-se que, os meses em que não houve precipitações foram maio, junho e julho, e isso está associado aos fatores climáticos e meteorológicos atenuantes na área de estudo, considerando que é entrada do solstício de inverno, onde há restrições hídricas devido ao regime pluviométrico.

O mês de agosto o qual foi analisado neste estudo e considerado mês seco, teve média pluviométrica de $2,4 \mathrm{~mm}$. Já o mês de outubro apresentou uma média de $83,7 \mathrm{~mm}$, e inicia-se o período chuvoso para a área de estudo.

Diante dessa premissa, essa variação pluviométrica é um dos elementos que influenciam na distribuição do Saldo de Radiação, considerando o consumo energético dos corpos na superfície.

Na figura 4 estão os mapas de Saldo de radiação para os períodos: 08/08/2016 e 27/10/2016: 


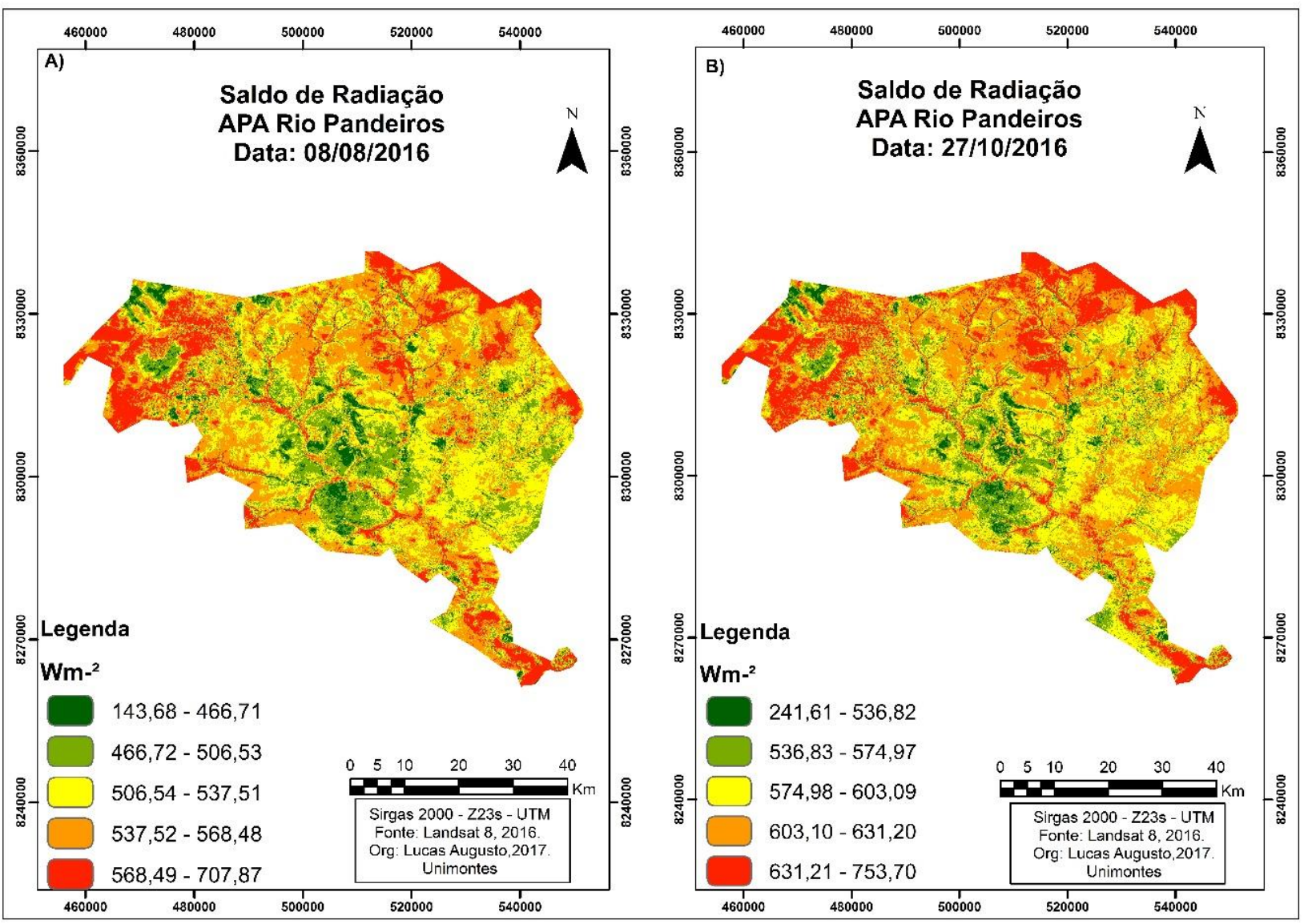

Figura 4. Mapas de Saldo de Radiação para os períodos analisados.

De acordo com os mapas A e B, observa-se que, o saldo de radiação variou de $142,68 \mathrm{Wm}^{2} \mathrm{e}$ $707,87 \mathrm{Wm}^{-2}$ para a data 08/08/2016 na APA Rio Pandeiros e de 241,61 $\mathrm{Wm}^{-2}$ a $753,70 \mathrm{Wm}^{-2}$ para a data $27 / 10 / 2016$.

É perceptível que há diferenças nos valores de saldo de radiação ao comparar os dois períodos analisado, sendo que no período seco (08/08/2016) o saldo de radiação foi menor, com média de $533,68 \mathrm{Wm}^{2}$, já o período chuvoso (27/10/2016) obteve valor médio de $603,20 \mathrm{Wm}^{2}$, isso podendo estar associado às influências que os índices pluviométricos podem ocasionar.

Para analisaro saldo de radiação em diferentes usos da Terra, coletou-se as amostras ( 5 pontos amostrais) em ambiente computacional, da posse dessas amostras, montou-se duas tabelas (5 e 6) com os valores do saldo de radiação por uso da Terra. 
Tabela 5 - Pontos amostrais (08/08/2016).

\begin{tabular}{|c|c|c|c|c|c|c|c|c|c|}
\hline $\begin{array}{l}\text { Amostra } \\
\mathrm{s}\end{array}$ & $\begin{array}{l}\text { Mata } \\
\text { Seca }\end{array}$ & $\begin{array}{l}\text { Cerrad } \\
\text { o }\end{array}$ & $\begin{array}{l}\text { Vered } \\
\text { a }\end{array}$ & $\begin{array}{l}\text { Campo } \\
\text { Cerrad } \\
\text { o }\end{array}$ & $\begin{array}{l}\text { Pastage } \\
\mathrm{m}\end{array}$ & $\begin{array}{l}\text { Solo } \\
\text { Expost } \\
\text { o }\end{array}$ & $\begin{array}{l}\text { Agricultur } \\
\mathrm{a}\end{array}$ & $\begin{array}{l}\text { Aflorament } \\
\text { o Rochoso }\end{array}$ & Água \\
\hline P1 & $\begin{array}{c}557,3 \\
3\end{array}$ & 607,72 & 627,53 & 505,57 & 480,91 & 438,73 & 527 & 513,08 & $\begin{array}{c}621,2 \\
5\end{array}$ \\
\hline $\mathrm{P} 2$ & 555 & 605,7 & 652,47 & 456,05 & 479,25 & 441,15 & 519,88 & 511,11 & 661 \\
\hline P3 & 571 & 600,4 & 623,59 & 503,74 & 478,51 & 472,46 & 521,25 & 502 & 675,5 \\
\hline P4 & $\begin{array}{c}588,3 \\
3\end{array}$ & 596,35 & 625,65 & 501,02 & 476,38 & 423 & 552 & 517,67 & 677 \\
\hline P5 & 591,5 & 602,5 & 640,21 & 506,83 & 499,86 & 435,22 & 498,28 & 508 & $\begin{array}{c}663,3 \\
3\end{array}$ \\
\hline
\end{tabular}

Fonte: Análise por Modelo SEBAL Org. LAPS, 2017.

Tabela 6- Pontos amostrais (27/10/2016).

\begin{tabular}{|c|c|c|c|c|c|c|c|c|c|}
\hline $\begin{array}{l}\text { Amostra } \\
\mathrm{s}\end{array}$ & $\begin{array}{l}\text { Mata } \\
\text { Seca }\end{array}$ & $\begin{array}{l}\text { Cerrad } \\
\text { o }\end{array}$ & $\begin{array}{l}\text { Vered } \\
\mathrm{a}\end{array}$ & $\begin{array}{l}\text { Campo } \\
\text { Cerrad } \\
\text { o }\end{array}$ & $\begin{array}{l}\text { Pastage } \\
\mathrm{m}\end{array}$ & $\begin{array}{l}\text { Solo } \\
\text { Expost } \\
\text { o }\end{array}$ & $\begin{array}{l}\text { Agricultur } \\
\text { a }\end{array}$ & $\begin{array}{l}\text { Aflorament } \\
\text { o Rochoso }\end{array}$ & Água \\
\hline P1 & $\begin{array}{c}658,2 \\
4\end{array}$ & 663,01 & 671,83 & 530,29 & 562,71 & 496,39 & 532,1 & 597,56 & $\begin{array}{c}732,6 \\
7\end{array}$ \\
\hline $\mathrm{P} 2$ & 659,4 & 642,27 & 686,35 & 491,92 & 555,36 & 466,42 & 589,83 & 598,5 & $\begin{array}{c}733,6 \\
7\end{array}$ \\
\hline P3 & $\begin{array}{c}655,7 \\
7\end{array}$ & 657,92 & 696,38 & 504,37 & 595,86 & 494,63 & 549,09 & 595 & 727,5 \\
\hline P4 & $\begin{array}{c}644,0 \\
5\end{array}$ & 650,85 & 670,18 & 516,28 & 562,55 & 474,08 & 589,13 & 586,12 & 730 \\
\hline P5 & $\begin{array}{c}659,5 \\
4\end{array}$ & 661,27 & 677,8 & 510,92 & 578,97 & 492 & 589,17 & 592,41 & 734,5 \\
\hline
\end{tabular}

Fonte: Análise por Modelo SEBAL Org. LAPS, 2017.

Após a coleta das amostras fez-se o cálculo de média para todos os valores dos pontos amostrais dos usos da Terra, a fim de analisar a curva do saldo de radiação nos usos da Terra em gráfico (gráfico 2) comparando o período seco e o chuvoso. 


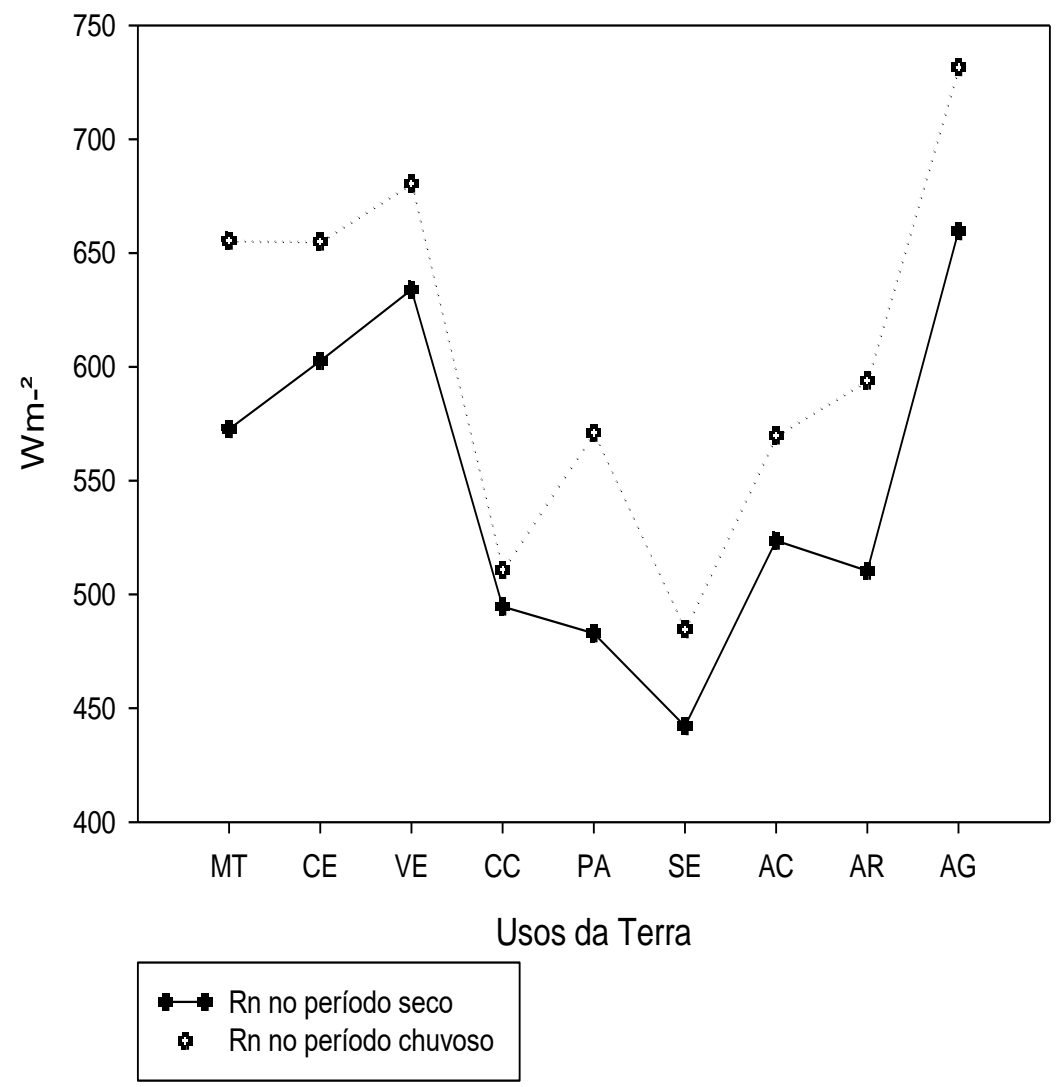

Gráfico 2. Médias do Saldo de Radiação para diferentes usos da Terra para nos períodos seco e chuvoso ${ }^{1}$. Fonte. Análise por modelo SEBAL. Org. LAPS, 2018.

Por meio de produtos MODIS, Filgueiras et al., (2013) analisaram o saldo de radiação e a evapotranspiração real no período de 15/09/2010 para o Norte de Minas Gerais; o Rn para esta mesorregião variou entre 470 e $640 \mathrm{Wm}^{2}$.

No que concerne às amostras de Saldo de radiação para as áreas de Mata Seca, seus valores variaram de $555 \mathrm{Wm}^{-2}$ a $591,5 \mathrm{Wm}^{-2}$ no período seco, sendo 08 de Agosto de 2016, a média das amostras foi estimada em 572,63 $\mathrm{Wm}^{2}$. Já para o período chuvoso os valores variaram de 644,05 $\mathrm{Wm}^{2}$ e $659,4 \mathrm{Wm}^{2}$, com valor médio de 655,4 $\mathrm{Wm}^{2}$.

Os valores encontrados nesta pesquisa são similares aos encontrados por Veloso (2013) tendo valor médio de $584,55 \mathrm{Wm}^{2}$ ao mensurar os componentes do balanço de radiação e energia no projeto Jaíba no Norte de Minas Gerais.
Esta diferença nos valores de Saldo de radiação para as áreas de mata seca, estão relacionados à sazonalidade climática da área de estudo. Sendo que no período de inverno a mata seca sofre alterações em sua arquitetura foliar, imprimindo assim quedas nas taxas de saldo de radiação e no período chuvoso processo contrário acontece, sofrendo aumentos em seus valores de saldo de radiação, este comportamento corrobora com estudos de Veloso et, al., (2017), sendo que esses autores obtiveram no período seco para as áreas de mata seca menores valores de saldo de radiação, e maiores valores no período chuvoso.

No tocante às áreas de Cerrado, os seus valores amostrais variaram de $596,35 \mathrm{Wm}^{-2}$ a $607,72 \mathrm{Wm}^{2}$ no período denominado seco (08/08/2016), com valor médio estimado em $602,53 \mathrm{Wm}^{2}$. Tangente às variações no período chuvoso, o saldo de radiação para os pontos

\section{${ }^{1}$ Significados:}

MT - Mata Seca; CE - Cerrado; VE - Vereda; CC - Campo Cerrado; PA - Pastagem; SE - Solo Exposto; AC - Agricultura; AR - Afloramento Rochoso; AG - Água. 
amostrais variou de $650,95 \mathrm{Wm}^{2}$ a $663,01 \mathrm{Wm}^{2}$, com valor médio estimado em $655,06 \mathrm{Wm}^{2}$. É notório que ocorre processo semelhante ao que houve com as áreas de mata seca, onde o saldo de radiação no período seco foi menor e no período chuvoso obteve aumentos. Autores como Lins et al., (2017) encontraram valores de Rn na ordem de 11 a $694 \mathrm{Wm}^{-2}$, salientando que os maiores valores foram para áreas com vegetação densa.

Isto associa-se aos aspectos da vegetação, sendo que no período de inverno o Cerrado sofre alterações naturais em sua fenologia, já que a disponibilidade hídrica neste período tende a ser menor e com isso, seus estômatos tendem a se fechar lentamente, imprimindo em menores trocas de energia para os processos biológicos do Cerrado. Este processo é reverso no período chuvoso, pois há maior disponibilidade hídrica e com isso as trocas de energia por saldo de radiação tende a ser mais elevadas. Machado et al., (2014) encontraram valores do Rn de 600 e $750 \mathrm{Wm}^{2}$ nos meses de agosto (no ano de 2006) e Janeiro (em 2011) para a reserva de Saltinho em Pernambuco.

As áreas de vereda na APA Rio Pandeiros, tanto período seco quanto no chuvoso, mantiveram valores de saldo de radiação elevados, tendo média de $633,89 \mathrm{Wm}^{2}$ para o período seco e, $680,51 \mathrm{Wm}-$ 2 de média para o período chuvoso, observa-se assim o comportamento de acréscimo em função da sazonalidade climática, no entanto, vale ressaltar que a umidade em áreas de veredas propicia também os valores elevados de saldo de radiação. Esta umidade é advinda das características fenológicas, hidrográficas e geomorfológicas das áreas de veredas.

No tocante às áreas mapeadas como campo cerrado, observou-se semelhança em seus valores de saldo de radiação para com as áreas de pastagens. No período seco, o saldo de radiação variou de 456,05 $\mathrm{Wm}^{-2}$ a 506,03 $\mathrm{Wm}^{2}$, com valor médio estimado em 494,64 $\mathrm{Wm}^{2}$. Já no período chuvoso os seus valores variaram entre 491,92 $\mathrm{Wm}^{2}$ e $530,29 \mathrm{Wm}^{2}$, com valore médio estimado em $510,76 \mathrm{Wm}^{2}$.

Ao mencionar que os valores de saldo de radiação para áreas de campo cerrado eram semelhantes às áreas de pastagem, faz-se referência principalmente para o período seco, onde o valor médio das áreas de pastagem foi de $482,98 \mathrm{Wm}^{2}$ $\mathrm{e}$, estes valores se assemelham devido às características fenológicas das duas classes de uso da Terra.

Para o período chuvoso, o valor médio das áreas de pastagem foi estimado em 571,09 $\mathrm{Wm}^{2}$, corroborando com valores estimados por Veloso (2013), que estimou valor médio para áreas de pastagens em 553,49 $\mathrm{Wm}^{2}$. Macedo et al (2014) encontraram valores na ordem de 473,2 e 493,9 W $\mathrm{m}^{-2}$ nos meses de abril e agosto de 2009 para áreas com pastagem e solo exposto naSub-Bacia do Ribeirão Marimbondo.

Os menores valor de saldo radiativo encontrados para esta pesquisa são destinados às áreas de solo exposto, tanto em conformidade com o período seco quanto para o período chuvoso. Os valores médios foram estimados em $442,11 \mathrm{Wm}^{2}$ (período seco) e 484,7 $\mathrm{Wm}^{2}$ (período chuvoso). Estas médias são justificadas pela falta de vegetação nessas classes, e, isso acarreta em maior reflexão de energia solar (albedo de superfície) para o espaço afetando diretamente o saldo de radiação, pois ao refletir mais energia, o saldo de radiação à superfície tende a ser menor.

As áreas destinadas aos sistemas agrícolas obtiveram médias de $523,68 \mathrm{Wm}^{2}$ (período seco) e $569,86 \mathrm{Wm}^{2}$ (período chuvoso). Os valores mantiveram determinada conformidade, isto porque as áreas de cultivos estão em constante processo de irrigação e, isso propicia variações do saldo de radiação e essa energia disponível é utilizada pelos cultivos para suas atividades biológicas.

Chama-se atenção para as áreas de afloramento rochoso, uma vez que, os valores médios de saldo de radiação foram relativamente elevados (sendo $510,37 \mathrm{Wm}^{2}$ no período seco e $593,92 \mathrm{Wm}^{2}$ no período chuvoso). No entanto, esses valores são explicitados devido a presença de vegetação nativa de cerrado e mata seca em áreas de afloramento rochoso e, com a presença dessas espécies o saldo de radiação tendeu a ser influenciado nas áreas de afloramento rochoso, devido as atividades biológicas das áreas de cerrado e mata seca.

Os maiores valores de saldo de radiação, foram estimados para áreas de corpos hídricos, sendo estimados em $659,61 \mathrm{Wm}^{2}$ para o período seco e 731,67 $\mathrm{Wm}^{2}{ }^{2}$ para o período chuvoso. Este comportamento de valores mais elevados de saldo de radiação para áreas de corpos hídricos se explicita devido a alta capacidade da água de armazenar calor.

Diante dos dados expostos, foi possível observar que a variabilidade dos usos da Terra inseridos na APA Rio Pandeiros influenciou na distribuição do saldo de radiação à superfície, bem como a sazonalidade climática, que demonstrou significativa influência nos valores, elevando-os no 
período chuvoso e tendo decréscimo no período seco.

\section{Considerações finais}

O saldo de radiação mostrou ter variação e sensibilidade de acordo com cada uso da Terra estabelecido para análise amostral, tendo maiores valores para corpos hídricos e em áreas de vegetação nativa, destacando as áreas de Veredas, com os maiores valores, tendo relação intrínseca com suas características bióticas.

Outra variação interessante do ponto de vista analítico ocorreu em relação à sazonalidade climática imposta a área de estudo, tendo acréscimos nos valores de saldo de radiação no período chuvoso e decréscimo no período seco.

Vale chamar a atenção para as técnicas atribuídas a este estudo, bem como técnicas de sensoriamento remoto, sobretudo o algoritmo SEBAL, que em conjunto mostraram-se ferramentas de grande potencial analítico.

Para estudos futuros, projeta-se analisar as variações de outros elementos do algoritmo SEBAL e com base empírica de trabalhos de campo detalhados.

Ao concluir essa pesquisa, pode-se inferir, a importância de analisar o saldo de radiação à superfície por meio de amostras em diferentes usos da Terra, uma vez que esse elemento variando de acordo com cada uso da Terra, pode servir de indicador de alterações nos sistemas ambientais.

\section{Referências}

Alves, L. E. R.; Gomes, H. B.; Santos, M. M.; Freitas, I. G. F. 2017. Balanço de RadiaçãoAtravés do Satélite Landsat-8 naBacia do Rio Pajeú. Revista do Departamento de Geografia 33, 117-127. DOI: $0.11606 /$ rdg.v33i0.124577.

Bezerra, J. M.; Moura, G. B. A.; Silva, B. B.; Lopes, P. M. O.; Silva, E. F. F. 2014. Parâmetrosbiofísicosobtidosporsensoriamentorem otoemregiãosemiárida do estado do Rio Grande do Norte, Brasil. RevistaBrasileira de EngenhariaAgrícola e Ambiental 18, 73-84.

Banco de Dados Geomorfométricos do Brasil. Disponívelem: http://www.dsr.inpe.br/topodata/. AcessoemSetembro de 2017.
CPRM. Companhia de Pesquisa Recursos Minerais. Disponível em: http://www.cprm.com.br. Acesso em Setembro de 2017.

Filgueiras, R.; Ribeiro, R. B.; Rodrigues, C. N. 2013.Estimativa da Evapotranspiração a partir de imagens do sensor MODIS aplicada à região Norte de Minas Gerais. ENCICLOPÉDIA BIOSFERA, Centro CientíficoConhecer - Goiânia 9, 10671078.

IBGE, Instituto Brasileiro de Geografia e Estatística, 2010. Disponível em: http://www.ibge.gov.br. Acesso em: Setembro de 2017.

ICMBio, Instituto Chico Mendes de Conservação da Biodiversidade, 2011. Disponível em: http://www.icmbio.gov.br. Acesso em: Setembro de 2017.

IGAM. Instituto Mineiro de Gestão das Águas, 2015. Disponível em: http://www.igam.com.br.

Acesso em: Setembro de 2017.

INMET. Instituto Nacional de Meteorologia, 2016. Disponível em: www.inmet.gov.br. Acesso em: Setembro de 2017.

INPE. Instituto Nacional de Pesquisas Espaciais, 2016. Disponível em: www.inpe.br. Acesso em Setembro de 2017.

Leite, M.E.; Fonseca, G.S.; Silva, L.A.; Leite, M.R. 2018. Geotecnologias aplicadas a estimativa da temperatura de superfície em diferentes usos e ocupações do solo na Área de Proteção Ambiental do Rio Pandeiros - Minas Gerais. Caderno de Geografia 28, 490-509. DOI: 10.5752/P.23182962.2018v28n53p490-509.

Lins, F. A. C.; Araújo, D. C. S.; Silva, J. L. B.; Lopes, P. M. O.; Oliveira, J. D. A.; Silva, A. T. C. S. G. 2017. Estimativa de Parâmetros Biofísicos e Evapotranspiração Real no Semiárido Pernambucano Utilizando Sensoriamento Remoto. Irriga, Botucatu, IRRIGA \& INOVAGRI Edição Especial, 64-75.

Lopes, H. L.; Silva, B. B.; Pacheco, A. P. 2014. Distribuição Espacial do Saldo de Radiação e Fluxo de Calor no Solo no território de Itaparica, Nordeste do Brasil. Revista Brasileira de Cartografia 66, 233-244. 
Lopes, P. M. O.; Valeriano, D. M.; Silva, B. B.; Moura, G. B. A.; Silva, A. O. 2013. Simulação do saldo de radiação na Serra da Mantiqueira. Revista Brasileira deEngenharia Agrícola e Ambiental 17, 780-789. DOI: 10.1590/s141543661023000700013 .

Lu,D.; Li, G.; Moran, E.; Kuang, W. 2014. A comparativeanalysisof approaches for successionalvegetationclassification in theBrazilianAmazon, GIScience\& Remote Sensing 51, 695-709. DOI: $10.1080 / 15481603.2014 .983338$

Macedo, F. L.; Bertonha, L. J.; Rodrigues, R. A. F.; Silva, H. R. SILVA, B. B. Dalchiavon, F. C. 2014. Utilização de imagens digais TM - Landsat 5 para estimação da evapotranspiração real diária. Bol. geogr., Maringá 32, 101-120.

Machado, C. C.; Silva, B. B.; Albuquerque, M. B.; Galvíncio, J. D. 2014. Estimativa do balanço de energia utilizando imagens TM - Landsat 5 e o algoritmo SEBAL no litoral sul de Pernambuco. Revista Brasileira de Meteorologia 29, 55 - 67.

Matos, R. C. M.; Candeias, A. L. B.; Azevedo, J. R. G. 2016. Estimativa do Saldo de Radiação Instantâneo no entorno do reservatório de Itaparica - PE com uso de imagens orbitais. Revista Brasileira de Cartografia 68, 641-654.

MMA. Glossário. Disponível em: http://www.mma.gov.br. Acesso em Julho de 2018.

Oliveira, L. M. M.; Montenegro, S. M. G. L.; Silva, B. B.; Moura, A. E. S. S. 2015. Balanço de Radiação por Sensoriamento Remoto em Bacia Hidrográfica da Zona da Mata Nordestina. 2015. Revista Brasileira de Meteorologia 30, 16 - 28. DOI:10.1590/0102-778620130652.

Santos, C. A. C.; Wanderley, R. N.; Araújo, A. L.; Bezerra, B.G. 2014. Obtenção do Saldo de Radiação em áreas de pastagem e floresta na Amazônia (estação seca) através do sensor MODIS. Revista Brasileira de Meteorologia 29, $420-432$.

Silva, A. M.; Silva, R. M.; Silva, B. B. Determinação da Temperatura da Superfície e Estimativa do Saldo de Radiação e Evapotranspiração usando imagens Landsat e Dados Observados. 2015. Revista Brasileira de Cartografia 67, 1203-1216.

Silva, B. B.; Braga, A. C.; Braga, C.C.;Oliveira, L. M. M.; Montenegro, S. M. G. L.; Junior, B.B. 2016. Procedures for calculation of the albedo with OLILandsat 8 images: Application to the Brazilian semi-arid. RevistaBrasileira de EngenhariaAgrícola e Ambiental 20, 3-8. DOI:http://dx.doi.org/10.1590/1807-

1929/agriambi.v20n1p3-8

Silva, L. A.; Leite, M. R.; Veloso, G.A. 2017. NDVI como indicador de alterações nos sistemas de usos da Terra e no Albedo de Superfície no Município de Várzea da Palma (Minas Gerais). Revista GeoNordeste 2, 76-94.

Silva, L. A. P.; Leite, M. R.; Filho, R. M. Geotecnologias aplicadas ao mapeamento da evolução geográfica dos sistemas de usos da terra da bacia do rio Jatobá. GeoTemas 7, 93-108.

Sothe, C.; Liesenberg,E.;Almeida, C.M.; Schimalski, M. B. 2017. Abordagens para classificação do estádio sucessional da vegetação do Parque Nacional de São Joaquim empregando imagens Landsat-8 e Rapideye.BulletinofGeodeticSciences, 23 , 389-404. doi: 10.1590/S198221702017000300026

\section{USGS. UNITED STATED GEOLOGICAL} SURVE.2016. Disponível em: https://landsat.usgs.gov/using-usgs-landsat-8product. Acessado em: 06/08/2018.

Veloso, G. A 2013. Análise Espaço Temporal dos Componentes do Balanço de Radiação, Energia e Evapotranspiração, Usando Técnicas de Sensoriamento Remoto em Áreas Irrigadas do Projeto Jaíba/MG. Dissertação (Mestrado). Uberlândia, UFU.

Veloso, G. A.; Ferreira, M. E.; Silva, B. B. 2017. Determinação da evapotranspiração real diária em áreas irrigadas do projeto Jaíba (Minas Gerais, Brasil), mediante imagens Landsat 5-TM. Revista Cerrados 15, 53-76.

Vieiro, G.P.; Ferreira, J. H. D.; Arantes, E.J. 2014. Quantificação da demanda hídrica utilizando balanço de água no solo e levantamento agrícola por imagens de satélite. Irriga, Botucatu 19, 675693. 